\title{
Análise comparativa de modelos e práticas de gestão ambiental em pequenas e médias empresas do setor da construção civil a partir de estudos teóricos
}

\author{
Comparative analysis of models and practices of environmental management \\ in small and medium-sized enterprises from the civil construction industry \\ considering theoretical studies
}

\section{Analyse de modèles et pratiques de la gestionenvironnementaledans de petites et moyennesentreprisesselon des étudesthéoriques} \author{
medianas empresas a partir de estudios teóricos \\ Júlio César Borges da Silva* \\ Osvaldo Luiz Gonçalves Quelhas* \\ Marisa Fasura de Amorim*
}

Análisis comparativo de modelos y prácticas de gestión ambiental en pequeñas y

Recebido em 18/04/2016; revisado e aprovado em 23/09/2016; aceito em 18/10/2016

DOI: http:/ / dx.doi.org/10.20435/1984-042X-2017-v.18-n.1(12)

\begin{abstract}
Resumo: Este estudo foi elaborado com o objetivo específico de comparar modelos e práticas de gestão ambiental para empresas de pequeno e médio porte (PME) do setor da construção civil, por meio de uma análise comparativa de estudos de casos. Teve por objetivo, propor melhorias no desempenho ambiental. Esta revisão da literatura foi organizada de forma a buscar informações que respaldem o propósito quanto à importância da gestão ambiental das PME para a sociedade. Palavras-chave: produção mais limpa; construção civil; práticas de gestão ambiental.

Abstract: This study was prepared with the specific goal of comparing models and practices of environmental management for small and medium-sized enterprises (SMEs) from the civil construction industry, based on a comparative analysis of case studies gathered in the academic literature. It aimed to suggest improvements in environmental performance. The literature review was organized in order to seek for information that supports the purpose of environmental management of SMEs for society.
\end{abstract}

Key words: cleaner production; construction; environmental management practices.

Résumé: Le but de cetteétudeest de comparer des modèlesetpratiques de la gestionenvironnementalepour les petites et moyennesentreprises (PME) dans la constructioncivile par le moyend 'uneanalysecomparatived'études de cas, visant à proposer des améliorations de la performance environnementale. Une révisionbibliographique a étéfaiteportant sur l'importance de la gestionenvironnementale des PME pour la société.

Mots-clés: production plus propre; construction; pratiques de gestion de l'environnement

Resumen: Este estudio fue preparado con el objetivo específico de comparar modelos y prácticas de gestión ambiental para pequeñas y medianas empresas (PyMEs) del sector de construcción civil, teniendo como base un análisis comparativo de estudios de casos reunidos en la literatura académica. Tuvo el objetivo de proponer mejoras en el desempeño ambiental. Esta revisión de la literatura se organizó para buscar información que apoya el propósito de la importancia de la gestión ambiental de las PyMEs para la sociedad.

Palabras clave: producción más limpia; construcción civil; prácticas de gestión ambiental.

* Universidade Federal Fluminense (UFF), Niterói, Rio de Janeiro, Brasil. 


\section{INTRODUÇÃO}

Segundo o estudo "Perspectivas da População Mundial", realizado pela Organização das Nações Unidas (ONU, 2013), a população mundial atual é de 7,2 bilhões de pessoas. Entretanto as projeções de crescimento são de $12,5 \%$ para 2025 e, 33,33\% para 2050 se comparado a 2013.

Pressionadas por esse fato, as empresas vêm buscando desenvolver um número cada vez maior de produtos e serviços para atender às demandas dessa população. Em contrapartida, o impacto ambiental dos sistemas produtivos aumentou (TELLO; RIBEIRO, 2012).

Dessa forma, o conceito de desenvolvimento sustentável passou a buscar, em cada atividade, formas de diminuir os impactos ambientais e aumentar a justiça social dentro dos orçamentos disponíveis (CAIXA ECONÔMICA FEDERAL [CEF], 2010).

Os arranjos produtivos das empresas ocasionam impactos ambientais, que são extensivos a toda cadeia produtiva. A promoção humana, a equidade social e o ambiente saudável e ecologicamente equilibrado devem ser a base de uma sociedade sustentável. Dentro desse contexto, a sustentabilidade apresenta múltiplos aspectos como o físico, o biológico, o cultural, o socioeconômico, o jurídico, o institucional, o político e o moral. As práticas ambientais estão surgindo como uma resposta à redução dos efeitos nocivos causados pelas atividades empresariais (INSTITUTO DE DESENVOLVIMENTO HUMANO E SUSTENTAVEL [IDHS], 2004).

O modelo internacional de balanço social foi proposto pela Global Reporting Initiative (GRI), organização não governamental, internacional, com sede na Holanda, cuja missão era desenvolver e disseminar globalmente diretrizes para a elaboração de relatórios de sustentabilidade econômica, social e ambiental das organizações. No Brasil, em dezembro de 2005, a Bovespa e várias instituições - Associação Brasileira das Entidades Fechadas de Previdência Privada (ABRAPP), Associação Nacional dos Bancos de Investimento (ANBID), Associação dos Analistas e Profissionais de Investimento do Mercado de Capitais (APIMEC), Instituto Brasileiro de Governança Corporativa (IBGC), Internacional Finance Corporation (IFC), Instituto Ethos e Ministério do Meio Ambiente - decidiram unir esforços para criar um índice de ações que fosse um referencial para os investimentos socialmente responsáveis, o Índice de Sustentabilidade Empresarial (ISE) (NASCIMENTO et al., 2008).

Esse movimento fez com que a BM\&FBOVESPA (2014), que era a responsável pela congregação das empresas de capital aberto, passasse a desenvolver, a partir de 2012, ações voltadas à área de sustentabilidade. Essa decisão proporcionou a exposição das empresas com ações voltadas à área de sustentabilidade ou ações similares efetivamente realizadas. Empresas sem desenvolvimento sustentável deveriam explicar as razões para a não realização dessas ações. Essa nova exigência refletiu a pressão dos stakeholders sobre as companhias, que teriam que também controlar os riscos que estavam agregados às atividades que trouxessem grandes prejuízos financeiros às empresas, comprometendo sua imagem.

A cadeia produtiva na área da construção civil vem proporcionando impactos ambientais imensuráveis, que, devido às suas particularidades, acabaram se tornando significativos em escala global. Dentre os impactos diretos podem ser citados a produção de resíduos, que chega a ser de $40 \%$ do total de resíduos gerados pela sociedade, o grande consumo de água, que, na produção de cimento, chega ser responsável por $5 \%$ das emissões de gases de efeito estufa (ONU, 2012).

Diante desse contexto, foi observada a falta de um modelo nacional adequado 
para a redução dos impactos ambientais, no segmento das pequenas e médias empresas (PME) do setor da construção civil, no qual deveriam ser levados em consideração a viabilidade econômica, técnica e operacional. Nesse contexto, a gestão ambiental tornou-se o tema central desta pesquisa.

\section{OBJETIVO DA PESQUISA}

O objetivo geral da pesquisa é propor melhorias no desempenho ambiental dos canteiros de obras das pequenas e médias empresas da indústria da construção civil brasileira. O estudo foi desenvolvido a partir da revisão bibliográfica dos conceitos de gestão ambiental e da análise de modelos e práticas ambientais atualmente em uso.

Para o desenvolvimento dos objetivos específicos da pesquisa, foram analisadas práticas ambientais identificadas em artigos e estudos de casos nacionais e internacionais, de saber profissional e acadêmico, guias de construção sustentável e manuais de obras de construção civil. Foram identificados na literatura instrumentos de gestão ambiental que foram comparados com práticas descritas nas publicações e com o modelo de Produção mais Limpa $(\mathrm{P}+\mathrm{L})$, em uso atualmente em canteiros de obras. O estudo foi realizado a partir de exemplos apresentados em empresas de pequeno e médio porte da cidade de Porto Alegre e na cidade de Goiânia.

Como metodologia de pesquisa adotada neste trabalho, foi realizada uma revisão da literatura existente sobre o tema Gestão Ambiental Empresarial nos Canteiros de Obras para uma Produção mais Limpa. Também foram analisadas práticas ambientais trabalhadas nos canteiros de obras e relatadas em estudos bibliográficos. Como resultado, houve um estudo comparativo das práticas e teorias ambientais utilizadas.

\section{SETOR DA CONSTRUÇÃO CIVIL}

A cadeia produtiva da indústria da construção civil tem como produto final o bem edificado. Esse processo movimenta um conjunto complexo de atividades econômicas que vão desde a elaboração de projetos, a extração da areia, a produção de tijolos e o aporte financeiro (FEDERAÇÃO DAS INDÚSTRIAS DO ESTADO DE MINAS GERAIS [FIEMG], 2013).

Segundo Tello e Ribeiro (2012), a extensão da cadeia produtiva da construção civil é composta pelos segmentos da indústria de transformação, que produzem materiais de construção, por segmentos do comércio varejista e atacadista, e por várias atividades de prestação de serviços, tais como serviços técnico-profissionais, financeiros e seguros. Apesar de a cadeia produtiva da construção civil ser ampla, verifica-se que é subaproveitada quanto às ações de sustentabilidade. Segundo estudos da Associação Brasileira da Indústria de Materiais de Construção (ABRAMAT) e da Fundação Getúlio Vargas (FGV), essa cadeia produtiva teve em 2010, uma representatividade na produção total de aproximadamente R\$ 300 bilhões, o que equivale a $8,1 \%$ do PIB brasileiro, gerando 11,3 milhões de postos de trabalho.

A European Commission (2011) elaborou um Guia de Referência Sobre as Melhores Práticas de Gestão Ambiental da Construção. Nele, eram apresentadas as ações específicas para o setor de construção civil que poderiam ser implementadas durante todo o ciclo produtivo. $\mathrm{O}$ documento abrangia toda a cadeia de valor, desde o ordenamento do território em nível público até os estágios de fim de vida dos produtos de construção (edifícios ou obras civis). A publicação foi dividida em capítulos que abordam as melhores práticas de gestão ambiental, com indicadores específicos do setor e referência de excelência para ordenamento do território, projetos de construção, construção de edifício e remodelação, operação e 
manutenção de edifícios, desconstrução de edifício e obras de construção civil.

Para todas as etapas do ciclo de vida do setor, haverá um impacto ambiental a ser considerado e minimizado. Porém, so- mente por meio de um estudo detalhado, poderemos identificar as áreas críticas do processo a serem adequadas às boas práticas construtivas ambientais. Esse ciclo é demonstrado na Figura 1, que segue:

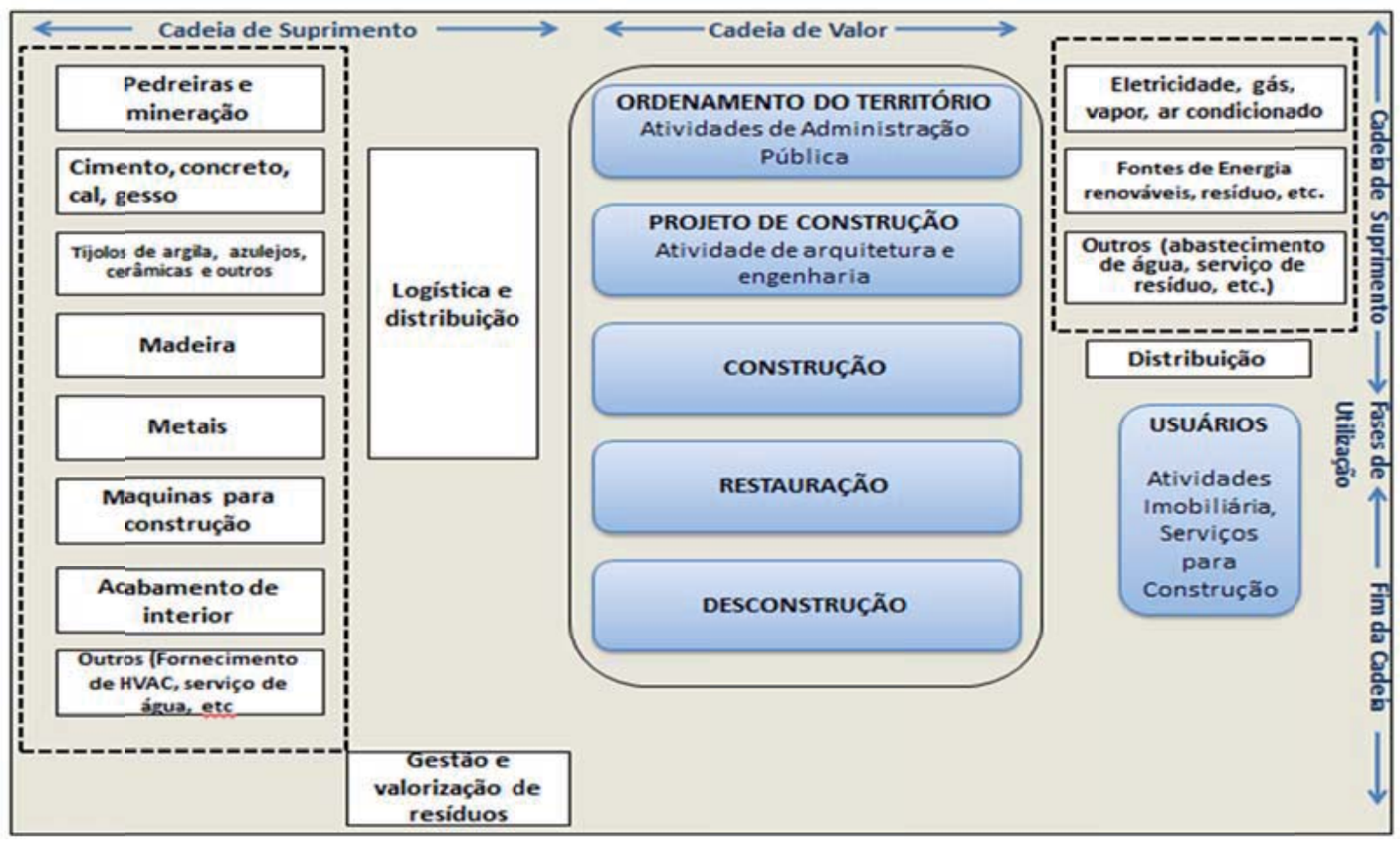

Figura 1 - Visão geral das entradas e saídas do setor de construção

Fonte: ONU (2012). (Adaptada pelos autores)

A consciência da necessidade da busca de soluções definitivas para o problema da poluição ambiental fez com que a Organização das Nações Unidas para o Desenvolvimento Industrial (ONUDI) e o Programa das Nações Unidas para o Meio Ambiente (UNEP) criassem um programa voltado para as atividades de prevenção da poluição. Nele, foi previsto a instalação de vários centros de Produção mais Limpa em países em desenvolvimento, para a formação de uma rede de informação. No Brasil, o Centro Nacional de Tecnologias Limpas (CNTL), é administrado pela Federação das Indústrias do Estado do Rio Grande do Sul (FIERGS) e pelo Departamento Regional do Rio Grande do Sul do Serviço Nacional de Aprendizagem Industrial (SENAI-RS). O Centro oferece às empresas interessadas suporte para desenvolver tais práticas (SENAI, 2014).

A sustentabilidade é um fenômeno relativamente novo no contexto empresarial. Especificamente na construção civil, as pressões exercidas pela opinião pública e pelos setores organizados da sociedade civil, em relação aos problemas ambientais, têm levado os governantes de muitos países a incorporar de modo crescente as dimensões ambientais em suas políticas públicas. Pode-se definir gestão ambiental como diferentes atividades administrativas e operacionais realizadas por empresas para abordar problemas ambientais decorrentes da sua atuação ou para evitar que eles ocorram no futuro (BARBIERI, 2011).

Segundo Tenório (2004), a questão da responsabilidade socioempresarial é um tema atual, polêmico e dinâmico, 
que envolve desde a geração de lucros pelos empresários até a implementação de ações sociais nos planos de negócios das companhias.

A maioria dos órgãos ambientais governamentais teve origem após a Conferência das Nações Unidas sobre o Meio Ambiente Humano, realizada em Estocolmo, em 1972. Essa ação foi um marco importante na percepção da globalização dos problemas ambientais. A partir dessa Conferência, a legislação ambiental começou a crescer vigorosamente contribuindo e vinculando questões ambientais às do desenvolvimento sustentável (BARBIERI, 2011).

Para Nascimento et al. (2008), o conceito de ecossistema do mercado incorpora conceitos da ecologia e da economia e pode ser definido como o conjunto das relações/interações que ocorrem entre os componentes e/ou variáveis do macroambiente (variáveis econômica, tecnológica, demográfica, político-legal, sociocultural, competitiva, ambiente natural), do microambiente (parceiros - fornecedores e intermediários de mercado, concorrentes, stakeholders externos), demanda (clientes, consumidores, usuários) e do ambiente interno (a organização em si mesmo, com todas as áreas e departamentos que ela possui).

\section{PRODUÇÃO MAIS LIMPA PARA PME}

Segundo o SENAI (2014), uma Produção mais Limpa (P+L) deve compreender uma estratégia econômica, ambiental e tecnológica integrada aos processos e produtos, de modo a aumentar a eficiência no uso de matérias-primas, água e energia, por meio da não geração, minimização ou reciclagem de resíduos produzidos em um processo produtivo.

Este conceito, $\mathrm{P}+\mathrm{L}$, surgiu por ocasião da Conferência Global Rio 92. Esse modelo de gestão desenvolvido pelo Programa das Nações Unidas para o Meio Ambiente (PNUMA) e ONUDI, surgiu em um esforço conjunto para instrumentalizar os conceitos e objetivos do desenvolvimento sustentável. A gestão ambiental deveria fazer parte da responsabilidade social e, como tal, deveria refletir o poder ampliado das empresas, de modo que pudessem de fato, se tornar parceiras do desenvolvimento sustentável (BARBIERI, 2011).

Tecnologias ambientais convencionais trabalhavam principalmente no tratamento de resíduos e nas emissões gerados pelos processos produtivos. Uma Produção mais Limpa tinha por objetivo a integração dos requisitos ambientais aos processos de produção, a fim de reduzir os resíduos e as emissões em termos de quantidade e periculosidade. Dentro desse processo, as ações poderiam ser divididas em níveis sendo: nível 1- contribuições para a minimização de resíduos e emissões na fonte; nível 2- reintegração de elementos ao processo produtivo de resíduos que não puderam ser eliminados (reciclagem interna); nível 3- resíduos que não pudessem ser reintegrados devendo ser reciclados por agentes externos à empresa (reutilização de resíduos e emissões). A Figura 2 apresenta o processo para uma produção mais limpa (SENAI, 2014). 


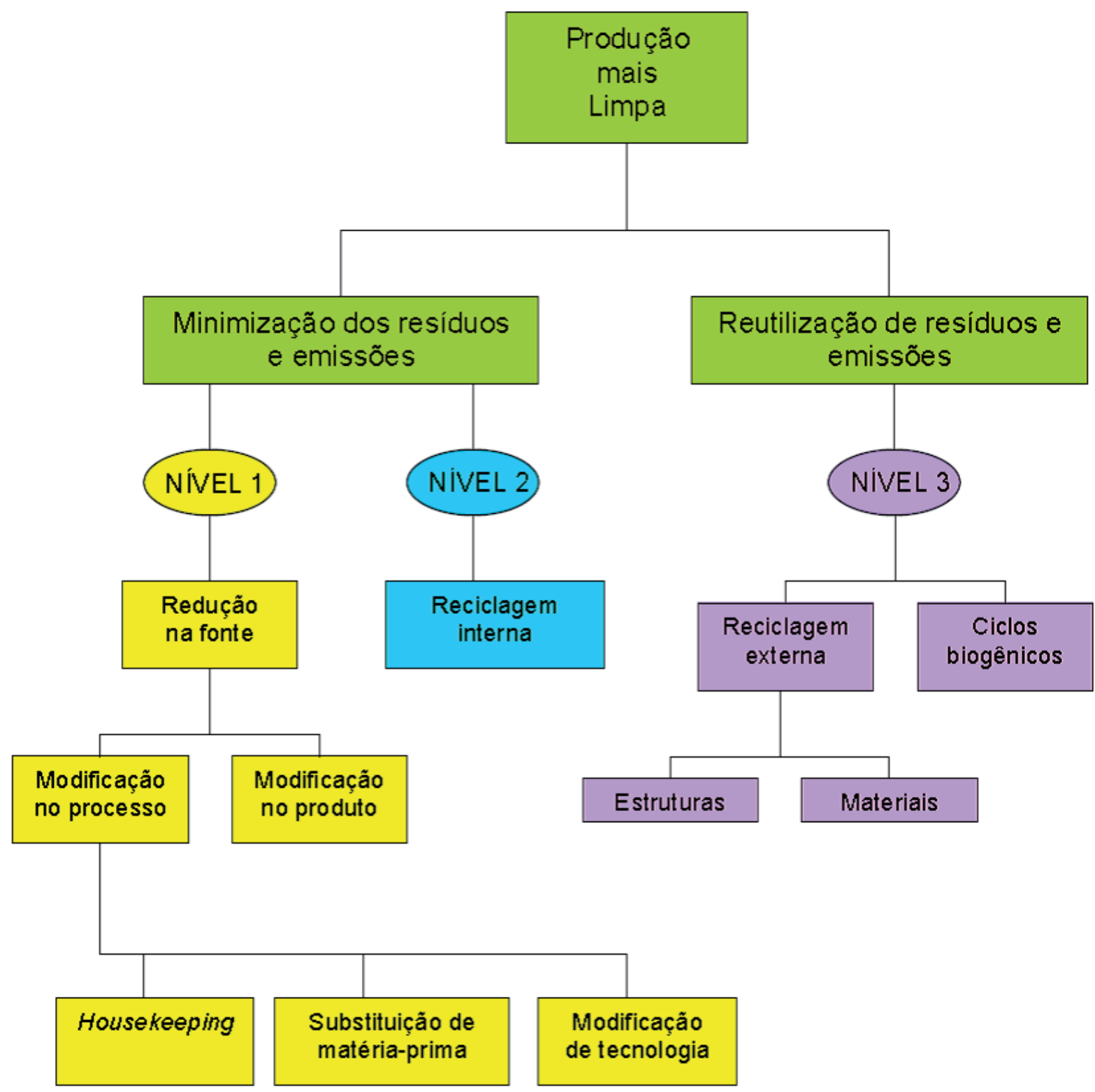

Figura 2 - Produção mais limpa - níveis de intervenção

Fonte: SENAI (2014).

O papel das empresas na promoção de um desenvolvimento que respeite o meio ambiente, não tem por fim apenas a necessidade de resolver os problemas ambientais acumulados ao longo dos anos, em decorrência das suas atividades, mas da ampliação da sua influência em todas as esferas da atividade humana. A percepção da globalização dos problemas ambientais é um fenômeno econômico, social, político e cultural que, embora não seja em essência novo, foi aprofundado nas duas últimas décadas do século passa- do devido a iniciativas da União Europeia, do Mercosul e do North American Free Trade Agreement (NAFTA) (BARBIERI, 2011).

Em 2001, a European Commission apresentou o Sistema Comunitário de Ecogestão e Auditoria que teve como reforço,a Norma EN/ISO 14001. A participação no sistema era voluntária e estendia-se a organizações públicas ou privadas com atividade na União Europeia e no Espaço Econômico Europeu (EEE) (EUROPEAN COMMISSION, 2011). 
Por meio de uma metodologia desenvolvida e apoiada pela United Nation Industrial DevelopmentOrganization (UNIDO), o Centro Nacional de Tecnologias Limpas oferecia aos setores produtivos alternativas para a identificação de técnicas que, quando implantadas em processos, permitiriam a minimização de resíduos sólidos, efluentes líquidos, emissões atmosféricas, aumento à eficiência energética e a racionalização do emprego da água. A implantação desse programa envolvia as etapas de planejamento e organização, pré-avaliação e diagnóstico, estudos de viabilidade técnica, econômica e ambiental e a implementação de opções e plano de continuidade (SENAI, 2014).

\section{AS PRÁTICAS NA CONSTRUÇÃO CIVIL}

Práticas ambientais no setor da construção civil vêm contribuindo nas questões relacionadas aos impactos na cadeia produtiva como o uso da água, da energia e da geração de resíduos (CEF, 2010).

A disposição inadequada de resíduos sempre foi uma das principais causas da degradação do meio ambiente. Essa situação afeta principalmente a qualidade de vida da população, dos ecossistemas e da disponibilidade dos recursos naturais. A geração dos resíduos da construção é realizada de forma difusa e se concentra em sua maior parte no pequeno gerador. Cerca de $70 \%$ dos resíduos gerados são provenientes de reformas, pequenas obras e das obras de demolição, que, em muitos casos, são coletados pelos serviços de limpeza urbana. O percentual restante (30\%) é proveniente da construção formal. Um processo construtivo sustentável deve envolver não só a otimização das etapas realizadas nos canteiros de obras, mas a possibilidade de aproveitamento de novas matérias-primas, para melhor integração homem-ambiente (SINDICATO DA INDÚSTRIA DA CONSTRUÇÃO

\section{CIVIL DO ESTADO DE SÃO PAULO} [SINDUSCON-SP], 2012).

Para Bueno e Rossignolo (2010), só após a elaboração da estratégia e do plano de ação da Agenda 21 que ocorreu em 1994, em Yokohama (Japão), que o desempenho ambiental passou a receber maior atenção. Nos contextos específicos das agendas locais e setoriais, surgiram as exigências de caráter ambiental, voltadas a parâmetros para edificações ambientalmente responsáveis. Isto levou à criação dos Sistemas de Certificação de Desempenho Ambiental de Edifícios.

Entre os métodos que vêm sendo utilizado com sucesso na prática para a redução dos resíduos de concreto está o da reciclagem dos resíduos, transformando-o em agregado. Um estudo comparativo realizado por Tam (2008), para averiguação dos custos e dos benefícios desse processo demonstrou que, na prática, a não reciclagem de resíduos representa perdas financeiras e comparado ao método de reciclagem de concreto. Ao final do estudo, foi comprovado que a reciclagem do concreto para agregado representa baixo custo para a indústria de construção e paralelamente auxilia no contexto ambiental (TAM, 2008).

Seguindo uma tendência mundial, o princípio dos 3R's (Reduzir, Reutilizar, Reciclar) classifica as formas de gestão de resíduos e prioriza a redução da geração na fonte. Em 1992, o Estado do Rio de Janeiro promulgou a Lei n. 2.011 que dispunha sobre a obrigatoriedade da implementação de programas de redução de resíduos. A Lei tinha por meta reduzir, anualmente, $10 \%$ do volume de resíduos, chegando a um montante de $50 \%$ sobre o total produzido. Agregado à Lei, o Plano de Gerenciamento de Resíduos (PGR) aperfeiçoou as oportunidades vinculadas ao correto gerenciamento de resíduos, reduzindo os riscos que estavam associados a essas atividades (FEDERAÇÃO DAS INDÚSTRIAS DO ESTADO DO RIO DE JANEIRO [FIRJAN], 2006). 
Oliveira (2012) desenvolveu em sua tese de doutorado uma metodologia de avaliação sobre sustentabilidade ambiental em canteiros de obra na fase de execução, o qual denominou ECO OBRA. A ferramenta que foi elaborada com o intuito de avaliar e classificar os canteiros de obra em relação à sustentabilidade ambiental propunha soluções e ações de redução dos impactos ambientais. Como parâmetro, a ferramenta classificava: médias menores que 5,00 - ambientalmente inviável; médias entre 5,00 e 7,50 - canteiro pouco sustentável; médias entre 7,50 e 9,00 - obra sustentável. Para avaliações cujas médias eram maiores que 9,00 o canteiro de obra classificava-se com grau de excelência em sustentabilidade. De doze canteiros de obras avaliados, nenhum canteiro atingiu a classificação como sustentável.

\section{ANÁLISE COMPARATIVA DE MODELOS E PRÁTICAS DE GESTÃO AMBIENTAL PARA PME}

O estudo de análise comparativa dos modelos de gestão ambiental voltados às práticas ambientais teve como propósito, identificar as ações desempenhadas nos canteiros de obras apresentadas na literatura existente. Para isso, foram analisados oito casos, sendo sete deles extraídos da página eletrônica do Centro Nacional de Tecnologias Limpas (CNTL) (SENAI, 2012) e um, do Guia de boas práticas em sustentabilidade na indústria da construção da Câmara Brasileira da Indústria da Construção (CBIC) (TELLO; RIBEIRO, 2012).

O Quadro um apresenta a relação das principais práticas de gestão ambiental $\mathrm{P}+\mathrm{L}$, utilizados nos canteiros de obras estudados. Foram identificadas as ações desenvolvidas e os respectivos benefícios econômicos e ambientais. Com exceção da empresa Pontal Engenharia Construções e Incorporações Ltda., que desenvolveu seus trabalhos no Estado de Goiás, as demais empresas possuíam seus empreendimentos em sua maioria nos Estados do Rio Grande do Sul e Santa Catarina. As áreas de atuação das empresas em sua maioria estavam voltadas para o segmento da construção civil pública e privada e para a consultoria imobiliária.

\begin{tabular}{|l|l|l|l|l|}
\hline \multicolumn{1}{|c|}{ Empresa } & $\begin{array}{l}\text { Área de implementação } \\
\text { da P+L }\end{array}$ & $\begin{array}{l}\text { Investimento } \\
\text { inicial para a } \\
\text { implementação } \\
\text { do sistema }\end{array}$ & $\begin{array}{c}\text { Benefício } \\
\text { econômico }\end{array}$ & Benefício ambiental \\
\hline $\begin{array}{l}\text { ARQUISUL } \\
\text { Arquitetura e } \\
\text { Construções } \\
\text { Ltda. }\end{array}$ & $\begin{array}{l}\text { - redução do desperdício } \\
\text { de madeira na etapa de } \\
\text { estrutura, fôrma e des- } \\
\text { fôrma das lajes; } \\
\text { - mudança no processo } \\
\text { de execução e de contro- } \\
\text { le efetivo para a geração } \\
\text { de resíduos de madeira } \\
\text { e compensado; } \\
\text { - redução da geração de } \\
\text { resíduos de tijolos na } \\
\text { etapa de alvenaria. }\end{array}$ & $\begin{array}{l}\text { - redução do cus- } \\
\text { to na produção } \\
\text { de laje no valor } \\
\text { de R\$ } 492,50\end{array}$ & $\begin{array}{l}\text { - redução no consumo } \\
\text { de madeira (redução de } \\
\text { vinte chapas de com- } \\
\text { pensado por laje ou 720 } \\
\text { chapas para toda obra, } \\
\text { o que representam } 1.344 \\
\text { me }^{2} \text { de chapa de compen- } \\
\text { sado). }\end{array}$ \\
\hline
\end{tabular}




\begin{tabular}{|c|c|c|c|c|}
\hline Empresa & $\begin{array}{c}\text { Área de implementação } \\
\text { da P+L }\end{array}$ & $\begin{array}{c}\text { Investimento } \\
\text { inicial para a } \\
\text { implementação } \\
\text { do sistema }\end{array}$ & $\begin{array}{l}\text { Benefício } \\
\text { econômico }\end{array}$ & Benefício ambiental \\
\hline $\begin{array}{l}\text { CFL Cons- } \\
\text { truções e } \\
\text { Incorporações } \\
\text { Ltda. }\end{array}$ & \begin{tabular}{|l|} 
- análise comparativa \\
entre o uso da argamas- \\
sa industrializada e a \\
produzida na obra; \\
- verificação da redução \\
dos resíduos de cimento, \\
areia, cal, aditivo e con- \\
sumo de energia elétrica.
\end{tabular} & $\begin{array}{l}\text { - não houve } \\
\text { investimento } \\
\end{array}$ & $\begin{array}{l}\text { - desvantagem } \\
\text { econômica de R\$ } \\
\text { 2.442,27 em rela- } \\
\text { ção à argamassa } \\
\text { industrializada, } \\
\text { considerando- } \\
\text {-se custos com } \\
\text { matéria-prima e } \\
\text { mão de obra. }\end{array}$ & $\begin{array}{l}\text { - a utilização da argamas- } \\
\text { sa industrializada con- } \\
\text { some aproximadamente } \\
15.504 \mathrm{~kg} \text { a menos de areia } \\
\text { do que a virada em obra; } \\
\text { - resíduos de embalagem } \\
\text { da massa industrializada } \\
\text { é aproximadamente } 2,5 \\
\text { vezes maior que a virada } \\
\text { em obra. }\end{array}$ \\
\hline $\begin{array}{l}\text { GC Engenha- } \\
\text { ria Ltda. }\end{array}$ & $\begin{array}{l}\text { - redução da poeira, do } \\
\text { ruído da obra e da área } \\
\text { de armazenamento. }\end{array}$ & $\begin{array}{l}\text { - não houve } \\
\text { investimento }\end{array}$ & $\begin{array}{l}\text { - o planejamento } \\
\text { na fase de projeto } \\
\text { reduz os custos da } \\
\text { obra em torno de } \\
\mathrm{R} \$ 1.389,25 \text { (valor } \\
\text { percentual da dife- } \\
\text { rença é de } 127 \%) .\end{array}$ & $\begin{array}{l}\text { - redução na geração de } \\
\text { resíduo de aproximada- } \\
\text { mente cinco } \mathrm{m}^{3} \text {. }\end{array}$ \\
\hline $\begin{array}{l}\text { Mel Nick } \\
\text { Construções } \\
\text { Ltda. }\end{array}$ & $\begin{array}{l}\text { - redução do resíduo e } \\
\text { do custo do porcelana- } \\
\text { to pela otimização das } \\
\text { condições globais do } \\
\text { processo produtivo }\end{array}$ & $\begin{array}{l}\text { - não houve } \\
\text { investimento }\end{array}$ & $\begin{array}{l}\text { - redução estima- } \\
\text { da de } 37 \mathrm{~m}^{2} \text { de } \\
\text { piso de porcelana- } \\
\text { to (economia po- } \\
\text { tencial aproxima- } \\
\text { da de } R \$ 4.000,00) .\end{array}$ & $\begin{array}{l}\text { - redução da geração de } \\
\text { resíduo }\end{array}$ \\
\hline $\begin{array}{l}\text { R. Correa } \\
\text { Engenharia } \\
\text { Ltda. }\end{array}$ & $\begin{array}{l}\text { - redução do resíduo } \\
\text { cerâmico e análise da } \\
\text { geração de resíduos na } \\
\text { execução de argamassa } \\
\text { para o reboco interno }\end{array}$ & $\begin{array}{l}\text { - não houve } \\
\text { investimento }\end{array}$ & $\begin{array}{l}\text { - redução de per- } \\
\text { da de } 13 \%,(\mathrm{R} \$ \\
6.093,77) .\end{array}$ & $\begin{array}{l}\text { - redução da quantidade } \\
\text { de resíduos de tijolos (53 } \\
\left.\mathrm{m}^{3}\right) \text {. }\end{array}$ \\
\hline $\begin{array}{l}\text { Obra Pronta } \\
\text { Projetos e } \\
\text { Execução de } \\
\text { Engenharia } \\
\text { Ltda. }\end{array}$ & $\begin{array}{l}\text { - redução da geração de } \\
\text { resíduo de gesso acarto- } \\
\text { nado. }\end{array}$ & $\begin{array}{l}\text { - não houve } \\
\text { investimento }\end{array}$ & $\begin{array}{l}\text { - economia de } \\
\text { R\$ 80,00/andar } \\
\text { na aplicação das } \\
\text { placas; } \\
\text { - economia total } \\
\text { por meio da re- } \\
\text { dução dos insu- } \\
\text { mos no valor de } \\
\text { R\$ 1.120,00. }\end{array}$ & $\begin{array}{l}\text { - redução do resíduo } \\
\text { gerado de } 322 \mathrm{~m}^{2} \text { de } \\
\text { chapas para } 280 \mathrm{~m}^{2}(13 \% \\
\text { do total global); } \\
\text { - reaproveitamento de } \\
10 \% \text { das chapas de gesso } \\
\text { acartonado. }\end{array}$ \\
\hline $\begin{array}{l}\text { Escritório de } \\
\text { Engenharia } \\
\text { Joal Teitel- } \\
\text { baum Ltda. }\end{array}$ & $\begin{array}{l}\text { - redução na geração de } \\
\text { entulhos; } \\
\text { - redução de riscos ambien- } \\
\text { tais (resíduo Classe A); } \\
\text { - criação da central de } \\
\text { tratamento de resíduos } \\
\text { de pintura no canteiro } \\
\text { de obras. }\end{array}$ & $\begin{array}{l}\text { - não houve } \\
\text { investimento }\end{array}$ & $\begin{array}{l}\text { - redução de cus- } \\
\text { to }(\mathrm{R} \$ 1.196,76) \\
\text { provenientes da } \\
\text { venda das emba- } \\
\text { lagens de tinta. }\end{array}$ & $\begin{array}{l}\text { - reaproveitamento de } \\
\text { embalagens de tintas. }\end{array}$ \\
\hline \begin{tabular}{|l|} 
Pontal En- \\
genharia \\
Construções e \\
Incorporações \\
Ltda.
\end{tabular} & $\begin{array}{l}\text { - redução na utilização } \\
\text { de matérias primas, por } \\
\text { meio da racionalização } \\
\text { de procedimentos e } \\
\text { mudanças nos arranjos } \\
\text { produtivos dos canteiros } \\
\text { de obras. }\end{array}$ & $\begin{array}{l}\text { - em } 2010 \text { a em- } \\
\text { presa a conquis- } \\
\text { tou cinco certi- } \\
\text { ficações - NBR } \\
\text { ISO 9001, PBQP- } \\
\text {-H, NBR 16001, } \\
\text { OHSAS 18001 e } \\
\text { NBR ISO 14001. }\end{array}$ & $\begin{array}{l}\text { - economia de } \\
\text { mais de } \mathrm{R} \$ \\
300.000,00 \text { para } \\
\text { uma obra de cer- } \\
\text { ca de } 21 \text { mil m². }\end{array}$ & $\begin{array}{l}\text { - o índice de descarte de } \\
41,31 \mathrm{~kg} / \mathrm{m}^{2}(68 \% \text { me- } \\
\text { nor }) .\end{array}$ \\
\hline
\end{tabular}

Quadro 1 - Síntese das práticas ambientais identificadas para o uso de Produção mais Limpa Fonte: Elaborado pelos autores (SENAI, 2012; TELLO; RIBEIRO, 2012). 
As práticas ambientais apresentadas pelas empresas nos canteiros de obras demonstraram os critérios de gestão de resíduos aplicados e que trouxeram como resultado a redução dos impactos econômicos e ambientais. Essas práticas, em obras de PME no setor da construção civil, reduziram, principalmente, os resíduos reutilizáveis ou recicláveis (resíduo tipo A), ocasionando a diminuição e o reaproveitamento dos resíduos e a redução do retrabalho com maior aplicação do modelo de Produção mais Limpa no seu nível 1 (redução dos impactos ambientais e do custo operacional nos canteiros de obras das PME).

Foram destacadas, no Quadro 1, as práticas ambientais de: redução de desperdícios de madeiras na etapa de estru- tura; mudanças no processo de execução e de controle para a gestão de resíduos de madeira e compensado; e redução de resíduos de tijolos na etapa de alvenaria (SENAI, 2012; TELLO; RIBEIRO, 2012).

Para o SENAI (2012), somente com o treinamento e a qualificação da mão de obra seria possível aproveitar melhor os insumos, minimizando a geração de resíduos, e fazer a adequada destinação das embalagens. Outro fator importante a ser observado refere-se à perfeita adequação do projeto à oferta de produtos, nas dimensões comerciais, principalmente para vidro e alumínio.

Como resultado, o Quadro 2 vem apresentar as principais práticas de $\mathrm{P}+\mathrm{L}$ utilizadas no estudo dos casos pelas empresas.

\begin{tabular}{|c|c|c|}
\hline Prática Ambiental & $\begin{array}{l}\text { Modelo Ambiental } \\
\qquad(\mathrm{P}+\mathrm{L})\end{array}$ & Análise Comparativa \\
\hline $\begin{array}{l}\text { Redução da geração de } \\
\text { resíduo tipo A }\end{array}$ & $\begin{array}{l}\text { Gestão de resíduos e } \\
\text { aplicação nível } 1\end{array}$ & $\begin{array}{l}\text { A análise comparativa das práticas com o modelo } \\
\text { de gestão ambiental concluiu que pequenas } \\
\text { medidas em um ambiente construtivo podem } \\
\text { resultar em economia financeira com redução do } \\
\text { impacto ambiental nos canteiros de obras. }\end{array}$ \\
\hline $\begin{array}{l}\text { Reaproveitamento de } \\
\text { resíduos de embalagens } \\
\text { de tintas }\end{array}$ & $\begin{array}{l}\text { Gestão de resíduos e } \\
\text { aplicação nível } 3\end{array}$ & $\begin{array}{l}\text { O modelo de gestão ambiental utilizado } \\
\text { pela empresa Joal Teitelbaum, foi o de } \\
\text { reaproveitamento de embalagens de tintas para } \\
\text { retorno à empresa, revertendo o custo de descarte } \\
\text { em benefício financeiro e redução do impacto } \\
\text { ambiental. }\end{array}$ \\
\hline $\begin{array}{l}\text { Redução do resíduo } \\
\text { cerâmico }\end{array}$ & $\begin{array}{l}\text { Gestão de resíduos e } \\
\text { aplicação nível } 1\end{array}$ & $\begin{array}{l}\text { O impacto direto devido à redução de materiais } \\
\text { gerou economia física e financeira. }\end{array}$ \\
\hline $\begin{array}{l}\text { Análise da geração de } \\
\text { resíduos na execução } \\
\text { de argamassa para o } \\
\text { reboco interno }\end{array}$ & $\begin{array}{l}\text { Gestão de resíduos e } \\
\text { aplicação nível } 1\end{array}$ & $\begin{array}{l}\text { A utilização da argamassa para o reboco interno } \\
\text { executada na obra gera economia para a empresa. }\end{array}$ \\
\hline $\begin{array}{l}\text { Redução da geração } \\
\text { de resíduo de gesso } \\
\text { acartonado }\end{array}$ & $\begin{array}{l}\text { Gestão de resíduos e } \\
\text { aplicação nível } 1\end{array}$ & $\begin{array}{l}\text { Economia de materiais trazendo redução do } \\
\text { impacto ambiental. }\end{array}$ \\
\hline $\begin{array}{l}\text { Redução do resíduo e } \\
\text { do custo do porcelanato }\end{array}$ & $\begin{array}{l}\text { Gestão de resíduos e } \\
\text { aplicação nível } 1\end{array}$ & Economia de produtos no processo produtivo. \\
\hline
\end{tabular}

Quadro 2 - Análise de modelos e práticas da gestão ambiental nas PME Fonte: Elaborado pelos autores. 
No estudo, o CNTL (SENAI, 2012) e o CBIC (TELLO; RIBEIRO, 2012) identificaram algumas práticas ambientais para as PME do setor de construção civil que podem, a médio prazo, auxiliar em futuras aplicações, sendo elas:

- Buscar novas metodologias de racionalização para processos de revestimento com argamassa;

- Estudar a substituição da massa corrida pela cal corrida no processo de pintura;

- Elaborar um estudo para avaliar o processo de aplicação de gesso e sua geração de resíduo desde a estocagem até os acabamentos;

- Priorizar a utilização de materiais para revestimentos externos com longa durabilidade a fim de reduzir as despesas com conservação;

- Elaborar estudos comparativos entre a aplicação de reboco e o gesso corrido para aplicação em tetos de apartamentos; - Elaborar estudos para a redução da geração de resíduos durante as instalações elétricas e hidráulicas, buscando a adequação dos blocos;

- Buscar a redução da geração de resíduos de tinta e de embalagem no processo de pintura;

- Elaborar um estudo avaliativo sobre a geração de resíduos nos revestimentos cerâmicos;

- Utilizar escoramento e fôrmas metálicas ou de polipropileno nos empreendimentos, em vez da madeira;

- Consolidar a cultura de P+L e de minimização dos resíduos na empresa;

- Aplicar rotinas de estudos de caso para diversos processos produtivos dentro das empresas de modo a racionalizar todas as etapas da obra;

- Implementar um controle mais rígido sobre os parâmetros de execução e geração de resíduos;

- Estudar alternativas de estocagens mais eficientes, buscando minimizar as perdas durante esse processo;

- Preservar os terrenos naturais, taludes, águas subterrâneas e vegetação local das obras;
- Reduzir os custos dos empreendimentos de modo a diminuir o uso de materiais por meio da melhoria contínua da qualidade, reciclagem e reaproveitamento de materiais e preservação ambiental;

- Buscar contato com os fornecedores visando à diminuição de resíduos de embalagens.

Para Bueno e Rossignolo (2010), o desenvolvimento de diretrizes para a criação de uma certificação direcionada ao contexto brasileiro deve contar com princípios sólidos. Dentre as bases, deve contar com técnicas consistentes que auxiliem na conscientização e difusão e, acima de tudo, no contexto nacional.

Para que haja uma efetiva construção e elaboração de uma metodologia ambiental nas empresas construtoras, faz-se necessário um diagnóstico da gestão onde fatores ligados ao consumo das águas, de energia e de resíduos sólidos possam ser mensuráveis e avaliáveis (OLIVEIRA, 2012).

O estudo revelou que o instrumento de gestão ambiental na prática utilizado pelo setor da construção civil, especificamente nos canteiros de obras, voltados ao modelo de uma $\mathrm{P}+\mathrm{L}$, atende mais especificamente a critérios da gestão de resíduos, sem desconsiderar a importância da aplicação nos critérios água e energia, trazendo como resultado benefícios financeiros e ambientais. Dentro dessa realidade, futuras ações ambientais em canteiros de obras nas pequenas e médias empresas do país podem ser realizadas como:

- A conscientização dos colaboradores do setor sobre a importância ambiental e suas implicações para o alcance dos objetivos sustentáveis ambientais nos empreendimentos construtivos;

- O uso da imagem empresarial com a adoção de práticas ambientais, contribuindo para uma avaliação positiva do empreendimento oferecido ao consumidor (bem agregado);

- A racionalização dos insumos nos canteiros de obras, contribuindo para a redução gradativa do consumo de mate- 
riais e de recursos naturais, aumentando a utilização de resíduos;

- A utilização de madeira certificada pelo Forest Stewadr ship Council (FSC);

- Implantação de Sistema de Monitoramento e Inventário da Geração de Resíduos;

- A utilização de sistemas híbridos que, conjugados, podem reduzir o custo e o uso de recursos naturais, como água e energia (sistemas que permitam um reaproveitamento de água da chuva, placas de energia fotovoltaicas e devolução de energia excedente à rede);

- Implementação de sistemas de lava-rodas para caminhões com decantação;

- Descarte adequado dos resíduos;

- Gestão de águas cinza, ecoeficiência energética, com aproveitamento de biogestores, iluminação zenital, sistemas de refrigeração e calefação integrados, aquecimento e geração solares. Sistemas eólicos de geração e conservação energética e aproveitamento de resíduos na geração de novos produtos;

- Uso racional dos materiais e uso de produtos e tecnologias sustentáveis (gerenciamento para reciclagem, utilização de concretos com uso de resíduos de obras);

- Uso drywall para a redução de alvenaria convencional e peso estrutural;

- Aproveitamento dos recursos naturais disponíveis (ventilação, iluminação natural, posição do sol) e utilização de contrapiso e tubulações com isolamento acústico;

- Aumento da resistência do concreto, mantendo o desempenho e reduzindo o consumo do aço das estruturas;

- Realização de encontros com empresários (startup) para apresentação de projetos inovadores voltados à construção civil.

As práticas ambientais descritas na literatura e relatadas neste estudo refletem ações e técnicas que, ao serem implementadas ao processo produtivo da construção civil, permitem a redução do impacto ambiental no segmento das PME's.
Como consequência, a comparação analítica dessas práticas resultaria em um aperfeiçoamento dessas ações, contribuindo para difusão do seu uso nos canteiros de obras, proporcionando melhorias no desempenho ambiental das PME's do setor da construção civil.

\section{CONCLUSÃO}

O número reduzido de ações ambientais nos canteiros de obras e a falta de um modelo nacional e de práticas para ações adequadas ao segmento das PME no setor da construção civil demonstram a falta de consciência ainda existente nas empresas, sobre a importância ambiental. Essa situação tende a prejudicar a concepção de ações práticas que poderiam ser implementadas como parte de um processo produtivo nesse setor.

As principais evidências observadas pela falta de aplicação de ações ambientais nos canteiros de obras demonstram o desconhecimento técnico e o compromisso da preservação ambiental por parte das empresas. Porém uma aplicação sistêmica de ações para redução dos impactos ambientais nos canteiros de obras pode resultar em ações reproduzidas por toda a extensão da cadeia produtiva, impactando no ciclo produtivo do setor.

Esse contexto pôde ser observado em práticas ambientais identificadas para o uso de uma Produção mais Limpa, utilizado pelas empresas estudadas, trazendo benefícios econômicos. Interessante observar que, para tal, nenhuma empresa necessitou fazer investimentos iniciais para a implementação do sistema, o que comprova que a ferramenta $\mathrm{P}+\mathrm{L}$ produz resultados positivos.

Paralelamente a isso, as empresa participantes do estudo obtiveram benefícios econômicos e ambientais, comprovando que práticas de modelos de gestão ambiental em pequenas e médias empresas trazem não só economia financeira, mas principalmente a redução do impacto ambiental nos canteiros de obras. 
Esta pesquisa demonstrou a viabilidade operacional e financeira para a operacionalização e incorporação de procedimentos que conduzam uma Produção mais Limpa com a redução dos impactos ambientais decorrentes dos processos produtivos da indústria da construção, minimizando custos operacionais e ambientais para as empresas.

\section{REFERÊNCIAS}

BARBIERI, José Carlos. Gestão ambiental: conceitos, modelos e instrumentos. 3. ed.São Paulo: Saraiva, 2011.

BM\&FBOVESPA. Relatório de sustentabilidade. São Paulo: Bovespa, 2014. Disponível em: <http://www.bmfbovespa.com.br/pt-br/ mercados/>. Acesso em: 4 mar. 2014.

BUENO, Cristiane; ROSSIGNOLO João Adriano. Desempenho ambiental de edificações: cenário atual e perspectivas dos sistemas de certificação. Revista Minerva - Pesquisa e Tecnologia, v. 7, n. 1, p. 45-52, 2010. Disponível em: <http://www.fipai.org.br/Minerva \%20 07(01)\%2006.pdf >. Acesso em: 3 mar. 2016.

CAIXA ECONÔMICA FEDERAL (CEF). Boas práticas para habitação mais sustentável. São Paulo: Páginas \& Letras, 2010. Disponível em: <http://downloads.caixa.gov.br/_ arquivos/>. Acesso em: $1^{\circ}$ jul. 2014.

EUROPEAN COMMISSION. Joint Research Centre, Institute for Prospective Technological Studies JRC report on Best Environmental Management Practice in the Building and Construction Sector. Spain, 2011. Disponível em: $<$ http://susproc.jrc.ec.europa.eu/activities/ emas/documents/ConstructionSector.pdf>. Acesso em: $1^{\circ}$ mar. 2014.

FEDERAÇÃO DAS INDÚSTRIAS DO ESTADO DE MINAS GERAIS (FIEMG). Contribuição econômica e social da cadeia produtiva da construção no estado de Minas Gerais. Belo Horizonte, 2013. Disponível em: <http:// www.sinduscon-mg.org.br/>. Acesso em: 15 mar. 2014.

FEDERAÇÃO DAS INDÚSTRIAS DO ESTADO DO RIO DE JANEIRO (FIRJAN). Manual de conservação e reúso da água na indústria. Rio de Janeiro, 2006. Disponível em: <https://www2.cead.ufv.br/sgal/files/>. Acesso em: 10 jun. 2014.

INSTITUTO DE DESENVOLVIMENTO HUMANO E SUSTENTÁVEL (IDHS). Sustentabilidade ambiental: Objetivo 7: Garantir a sustentabilidade ambiental. Belo Horizonte: PUC Minas, 2004. Disponível em: <http:// www.mma.gov.br/port/sdi/ea/deds/arqs/ objmil_sustamb.pdf $>$. Acesso em: 20 maio 2014.

NASCIMENTO, Luís Felipe; LEMOS, Ângela Denise da Cunha; MELLO, Maria Celina Abreu de. Gestão socioambiental estratégica. Porto Alegre, RS: Brookman, 2008.

ORGANIZAÇÃO DAS NAÇÕES UNIDAS (ONU). População mundial deve atingir 9,6 bilhões em 2050. Genebra, 2013. Disponível em: <http://www.onu.org.br/>. Acesso em: 9 maio 2014.

Programa das Nações Unidas para o Desenvolvimento (PNUD Brasil). Objetivos de Desenvolvimento do Milênio. 2012. Disponível em: <http:/ / www.pnud.org.br/ODM.aspx>. Acesso em: $1^{\circ}$ mar. 2014.

OLIVEIRA, Jorge Antonio da Cunha. Proposta de avaliação e classificação da sustentabilidade ambiental de canteiros de obras. Metodologia Eco Obra aplicada no Distrito Federal - DF. 2012. Tese (Doutorado em Estruturas e Construção Civil) - Universidade de Brasília, Df, 2012. Disponível em: <http://repositorio.unb.br/ JorgeAntonioCunhaOliveira.pdf $>$. Acesso em: 3 mar. 2016

SERVIÇONACIONALDE APRENDIZAGEM INDUSTRIAL (SENAI). Centro Nacional de Tecnologias Limpas. Porto Alegre, RS, 2014. Disponível em: <http://www.senairs.org. br/cntl/>. Acesso em: 9 maio 2014.

SINDICATODA INDÚSTRIA DA CONSTRUÇÃO CIVIL DO ESTADO DE SÃO PAULO (SINDUSCON-SP). Resíduos da construção civil e o estado de São Paulo. São Paulo, 2012. Disponível em: <http:/ / www.indusconsp. com.br/>. Acesso em: 9 maio 2014.

TAM, Vivian W. Y. Economic comparison of concrete recycling: a case study approach. Resources, Conservation and Recycling, v. 52, n. 5, p. 821-828, mar. 2008. Disponível em: <http:// dx.doi.org/10.1016/j.resconrec.2007.12.001>. Acesso em: 5 jun. 2014. 
TELLO, Rafael; RIBEIRO, Fabiana Batista. Guia CBIC de boas práticas em sustentabilidade na indústria da construção. Brasília: Câmara Brasileira da Indústria da Construção; Nova Lima: Fundação Dom Cabral, 2012. 160p. Disponível em: <http://www.cbic.org.
br/arquivos/Guia_de_Boas_Praticas_em_ Sustentabilidade_CBIC_FDC.pdf $>$. Acesso em: 10 maio 2014.

TENÓRIO, Fernando Guilherme. Responsabilidade social empresarial: teoria e prática. Rio de Janeiro: Fundação Getúlio Vargas, 2004.

\section{Sobre os autores:}

Júlio César Borges da Silva: Mestre em Engenharia Civil pela Universidade Federal Fluminense (UFF), área de concentração: Gestão, Produção e Meio Ambiente. Graduação em Administração de Empresas e Ciências Contábeis e Curso Superior complementar de Empreendedorismo pela UFF. Especialização (pós-graduação lato sensu) em Finanças Corporativas. E-mail: jcbate@gmail.com

Osvaldo Luiz Gonçalves Quelhas: Pós-Doutorado pela Universidade do Minho (UMINHO), Portugal. Doutorado em Engenharia de Produção pela Universidade Federal do Rio de Janeiro (UFRJ). Servidor Público, Enquadramento Funcional: Professor Titular, Regime: Dedicação exclusiva. E-mail: quelhas@latec.uff.br

Marisa Fasura de Amorim: Mestre em Engenharia Civil e Engenheira de Segurança do Trabalho pela UFF. Engenheira Civil pelao Centro Universitário Augusto Motta (Unisuam). Servidora da Universidade Federal Fluminense (Engenheira de Segurança do Trabalho, HUAP). E-mail: mfasura@gmail.com 